\title{
GLOBALIZACIÓN, ESTABILIDAD PRESUPUESTARIA Y COMUNIDADES AUTÓNOMAS*
}

\author{
Globalization, Budget Stability \\ and Autonomous Communities
}

\author{
José Luis García Guerrero ${ }^{1}$ \\ Profesor Titular (ApC) Derecho constitucional \\ Universidad de Castilla - La Mancha \\ http://dx.doi.org/10.18543/ed-67(1)-2019pp223-258
}

Recibido: 21.11.2018

Aceptado: 21.06 .2019

A mi maestro, Juan José Solozábal Echavarría

* Cómo citar / Citation 'Chicago-Deusto' (Autor-fecha / Author-date / Lista de referencias / Reference list entries): García Guerrero, José Luis. 2019. «Globalización, estabilidad presupuestaria y Comunidades Autónomas». Estudios de Deusto 67, n. ${ }^{\circ}$ 1: 223-258. http://dx.doi.org/10.18543/ed-67(1)-2019pp223-258.

Este capítulo fue defendido bajo el mismo título, por primera vez, el 9 de septiembre de 2016, como ponencia en el curso dirigido por SOLOZABAL ECHAVARRÍA, Juan José y ARAGÓN REYES, Manuel, «El Estado autonómico en acción», Universidad Autónoma de Madrid y Fundación Manuel Jiménez Abad. Posteriormente en el Congreso nacional Constitución financiera versus Constitución social, organizado por TEROL BECERRA, José Manuel, en la Universidad Pablo de Olavide de Sevilla el 25 de abril de 2017. Finalmente, como ponencia inaugural en el II Seminario Internacional Direitos da cidania na nova ordem mundial, Unochapecó (Brasil), el 11 de junio de 2018. La ponencia se integra en el proyecto de investigación Democracia y solidaridad en las integraciones económicas (DER 2017 83596-R).

1 orcid.org/0000-0003-2801-5741 


\section{Resumen}

El presente artículo aborda el embate de la globalización a la distribución territorial de los Estados. En particular, se centra en la incidencia de la globalización y de las normas sobre estabilidad financiera provenientes de organizaciones supranacionales en el ámbito competencial de las Comunidades Autónomas.

\section{Palabras clave}

Globalización; Estabilidad financiera; Comunidades Autónomas.

\section{Abstract}

The paper aims to study the onslaught of globalization to the territorial distribution of the State. In particular, it focuses on the impact of globalization and the rules on financial stability coming from supranational organizations in the field of competences of the Autonomous Communities.

\section{Keywords}

Globalization; Budget Stability; Autonomous Communities. 


\begin{abstract}
SUMARIO: I. LA GLOBALIZACIÓN. 1. La primera etapa de la globalización: los diferentes tipos de integraciones supraestatales. 2. La segunda etapa: los acuerdos comerciales en que una parte, al menos, es una integración económica. II. EL EMBATE DE LA GLOBALIZACIÓN A LA DISTRIBUCIÓN TERRITORIAL DEL PODER. III. AL ÁMBITO COMPETENCIAL DE LAS COMUNIDADES AUTÓNOMAS SEGÚN SE INTENSIFICA LA INTEGRACIÓN. IV. A SU AUTONOMÍA POLÍTICA (FINANCIERA). 1. A propósito de la soberanía. 2. Sobre la autonomía política y financiera. 3. El camino hacia la estabilidad presupuestaria. 4. La Ley Orgánica 2/2012, de 27 de abril, de Estabilidad Presupuestaria y Sostenibilidad Financiera. 4.1. Principios y afección a la autonomía política y financiera. 4.2. Medidas preventivas, correctivas y coercitivas. V. AL ESTADO SOCIAL (SANIDAD Y EDUCACIÓN). VI. CONCLUSIÓN. VII. BIBLIOGRAFÍA.
\end{abstract}

\title{
I. LA GLOBALIZACIÓN
}

La globalización evoluciona constante y raudamente, como puede apreciarse, a modo de ejemplo, siguiendo el Diccionario de la Real Academia de la Lengua ${ }^{2}$. En la nueva edición, con ocasión de su trigésimo centenario, en su cuarto significado referido a la economía, la define: «Proceso por el que las economías y mercados, con el desarrollo de las tecnologías de la comunicación, adquieren una dimensión mundial, de modo que dependen cada vez más de los mercados externos y menos de la acción reguladora de los Gobiernos». Además, ya no es necesario especificar «globalización económica», porque el segundo significado extiende el fenómeno al Derecho en general y al Derecho constitucional, en particular: «Extensión del ámbito propio de instituciones sociales, políticas y jurídicas a un plano internacional» $»^{3}$. En línea coincidente, el Fondo Monetario Internacional afirma que «La globalización es una interdependencia económica creciente del conjunto de países del mundo, provocada por el aumento del volumen y la variedad de las transacciones transfronterizas de bienes y servicios, así como de los flujos internaciones de capitales, al tiempo que se difunde acelerada y generalizadamente la tecnología $\rangle^{4}$.

${ }^{2}$ Sobre la evolución del término globalización en el Diccionario y, en general, sobre la materia, véase GARCÍA GUERRERO, José Luis, y MARTÍNEZ ALARCÓN, María Luz, Constitucionalizando la globalización, capítulo I, y en general vol. I y vol. II, Tirant Lo Blanch, Valencia, 2019.

${ }^{3} \mathrm{http}: / /$ dle.rae.es/?id=JFCXg0Z

${ }^{4}$ FONDO MONETARIO INTERNACIONAL, World Economic Outlook: Meeting the Challenges of Globalization in the Advanced Economies, Washington D.C., Mayo, 1997, p. 45. 
Cuando se analiza la globalización, desde una perspectiva constitucional, se observa que este fenómeno supone un embate al concepto racional normativo de Constitución ${ }^{5}$. A medida que se intensifica la globalización resultan afectados, en mayor o menor medida, los valores y los derechos fundamentales, los derechos constitucionales y, entre ellos, muy especialmente, los de los trabajadores, el principio democrático entendido en sentido amplio, la constitución económica, los impuestos, así como el propio Estado social e, incluso, algunos mandatos constitucionales como la protección del medio ambiente. Este amplio objeto de afección por la globalización, cuya mención no ha pretendido ser exhaustiva, no puede afrontarse en un artículo, por lo que el mismo quedaría acotado al embate que la globalización origina a la distribución territorial del poder en los Estados compuestos y muy incidentalmente al Estado social.

En el párrafo anterior se acaba de reseñar que a medida que se profundiza en la globalización resultan afectados una serie de ámbitos constitucionales en mayor o menor medida; luego el embate depende de la profundización de la globalización, lo que obliga, dentro de la misma, a diferenciar entre la liberalización multilateral y la bilateral. Esta última se refiere a las integraciones económicas, donde son discernibles dos etapas: una primera en que cabe distinguir distintos tipos de integraciones ${ }^{6}$, ordenadas de menor a mayor intensidad de la integración: Acuerdo de libre comercio, Unión aduanera, Mercado común y Unidad económica y monetaria supraestatal; y una segunda etapa de las integraciones que se diferencia por los actores en la medida en que, al menos, una de las partes en el acuerdo comercial es una integración económica. A continuación, se van a examinar sintéticamente estas categorías.

\section{La primera etapa de la globalización: Los diferentes tipos de integraciones supraestatales}

A partir de 1994, a los pocos años de la caída del muro de Berlín, y justo tras fundarse la Organización Mundial del Comercio (en adelante OMC), ésta trata de reactivar la liberación multilateral del comercio (una historia jalonada

5 VICIANO PASTOR, Roberto, «Problemas de legitimidad constitucional de las integraciones supranacionales», Cuadernos constitucionales de la Cátedra Fadrique Furiol, n. ${ }^{\circ}$ 67-68, 2009.

${ }^{6}$ Hay un cierto acuerdo doctrinal en atribuir la distinción de diferentes fases de integración por su intensidad a BALASSA, Bela, Teoría de la integración económica, Unión tipográfica editorial hispano-americana, México, 1964, p. 2. Una crítica doctrinal a esta posición, que no se comparte, en TORRENT, Ramón, La integración regional ante un nuevo cambio de paradigma: reflexiones desde una perspectiva histórica y comparada, Sieca, 2009, p. 62 nota 14. www.sieca.int/PortalData/Documentos/D2044BC3-FCD44FCD-9232A6CDF6E81666.pdf 
de éxitos vista en su conjunto), con el GATT de 1994 y con el Acuerdo General sobre el Comercio de Servicios. Tras el fracaso de esta iniciativa, promovió, con el apoyo de los Estados Unidos, decididamente, las integraciones económicas supraestatales ${ }^{7}$ (supranacionales) ${ }^{8}$ que consiguen, en una primera fase, en un ámbito territorial más reducido, el mismo objetivo.

La razón que explica esta apuesta por el bilateralismo, integraciones económicas, reside en que la vieja contraposición entre uniformidad y diversidad, como en tantas otras ocasiones en Derecho constitucional, es absolutamente clave en la globalización. El multilateralismo, las integraciones y su segunda etapa requieren de una cierta uniformidad entre los Estados para poder materializarse. Obviamente, esta uniformidad es necesaria en todos los campos, aunque es más conveniente en el ámbito económico y constitucional, piénsese en la economía de mercado, la unidad económica nacional y su correlato la unidad de mercado, la propiedad privada, la libertad de empresa o la tutela judicial efectiva. Por el contrario, la diversidad es un obstáculo muchas veces insalvable. Lógicamente esa uniformidad se consigue más fácilmente entre territorios geográficamente próximos, lo que explica el éxito de los cuatro tipos de integración de la primera etapa de la globalización?

Si se atiende a la mayor o menor intensidad de la integración económica, el primer tipo de integración de la primera fase de la globalización es el Acuerdo de libre comercio, aunque la mayor parte de la doctrina y la OMC utilizan la expresión Zona de libre comercio. En este artículo se van a utilizar indistintamente ambos términos. Estos instrumentos comerciales suelen ir precedidos de Acuerdos preferenciales de comercio (APC), que tienen por objeto preparar el futuro Acuerdo. Aquéllos tratan de liberalizar la circulación progresiva del mayor número posible de mercancías, pero suelen excluirse algunas especialmente sensibles, como la agricultura, la ganadería $o$ la pesca.

${ }^{7}$ La promoción por la OMC de las integraciones vuelve a intensificarse tras el nuevo fracaso de la liberalización multilateral en la Ronda de Doha, iniciada en Qatar en noviembre de 2001, hasta el punto que recoge en su normativa, concretamente en el artículo XXIV del GATT, dedicado a la aplicación territorial del tráfico fronterizo, la regulación de las uniones aduaneras y zonas [Acuerdos] de libre comercio.

${ }^{8}$ La doctrina internacionalista, comunitaria y económica sobre la globalización utiliza la expresión integración supranacional; sin embargo, este autor defiende como más correcto desde una perspectiva constitucional el término supraestatal, porque hay numerosos Estados plurinacionales.

9 Por este motivo, y muy acertadamente, el tercer significado del sustantivo «globalización» es definido por el Diccionario de la Real Academia de la Lengua de España como «Difusión mundial de modos, valores o tendencias que fomenta la uniformidad de gustos y costumbres». http://dle.rae.es/?id=JFCXg0Z 
El Acuerdo de libre comercio típico persigue la libre circulación de mercancías y de ciertos servicios entre los Estados que la integran. El objetivo se consigue eliminando aranceles progresivamente y haciendo desaparecer los contingentes de exportación hasta su total eliminación. En esta línea se prevén plazos temporales y se establecen diferencias por sectores económicos, dentro de éstos aparecen como especialmente problemáticos la agricultura, la ganadería y la pesca. Desde la firma del Acuerdo hasta su perfeccionamiento transcurren en la mayor parte de las ocasiones muchos años, a veces más de una década. El establecimiento de plazos, según los sectores, para la desaparición completa de los aranceles y de los contingentes es una forma de esperar una cierta uniformización en la materia en los diversos Estados que se integran, al tiempo que se busca preparar esos sectores para una competencia más intensa. Los aranceles y los contingentes no son los únicos instrumentos para obstaculizar la libre circulación de mercancías y servicios, los Estados emplean otros que podríamos calificar de indirectos, como son la divergencia normativa para autorizar la venta de mercancías o la diferente reglamentación para poder prestar servicios. Por esta razón todos los Acuerdos de libre comercio exigen una amplia implementación normativa y suelen contemplar regulaciones sobre origen de las mercancías y medidas fitosanitarias.

El Acuerdo de libre comercio requiere, como se acaba de indicar, una cierta uniformidad en el ámbito económico y en las instituciones constitucionales. Siempre se ha señalado que afecta únicamente a la política comercial y así es predominantemente, pero también incide en la política monetaria. Incluso más de lo que cabría imaginar. Un acuerdo de libre comercio no puede prosperar y mantenerse sin que la política monetaria, a través de los Bancos centrales de los Estados afectados, garantice una suave fluctuación entre las divisas concernidas. Las alteraciones en el valor de intercambio de las divisas pueden destruir el acuerdo comercial e iniciar guerras comerciales.

El elemento más relevante de la Unión aduanera es que toda la política comercial queda en manos de los órganos ejecutivos de la integración. Son éstos los encargados de fijar los aranceles y los contingentes, así como los demás instrumentos que se utilizan para indirectamente impedir el libre comercio y la prestación de servicios frente a terceros Estados. Creo que no se ha ponderado suficientemente la importancia de este elemento, porque el hecho de que la política comercial pase de los Estados integrados a los órganos ejecutivos de la integración implica que serán éstos los que firmen cualquier otro Acuerdo comercial con terceros Estados, directamente o a través de una persona jurídica instrumental. Es decir, que mientras un Estado forme parte de una Unión aduanera no podrá concluir acuerdos comerciales con terceros ${ }^{10}$.

${ }^{10}$ Esta consecuencia ha originado un controvertido debate en el Reino Unido con objeto de fijar su futura relación comercial con la Unión Europea. No obstante, se debe 
Finalmente, hay que destacar que la Unión aduanera, como se acaba de señalar, deja en manos de la integración toda la política comercial, pero engloba también a la política monetaria. Los Estados integrantes de la Unión verán mucho más restringida su libertad en política monetaria porque los márgenes de la misma serán más estrictos, al deber oscilar las divisas concernidas en márgenes más estrechos que en un Acuerdo de libre comercio. La consecuencia es que la Unión aduanera, de facto aunque no de Derecho, incluirá indirectamente partes relevantes de la política macroeconómica, porque una de sus vertientes, la comercial, está en manos de la Unión, otra vertiente, la monetaria, está fuertemente condicionada y la única libertad que conservan completamente los Estados es la política fiscal: ingresos (tributos) y gastos. El impulso de la OMC a las Uniones aduaneras como medio de avanzar en el multilateralismo se prueba una vez más, al haber previsto esta organización internacional también un estatuto tipo y las medidas a adoptar por los Estados que quieren constituirse en Unión aduanera, concretamente en el artículo XXIV del GATT.

El tercer tipo de integración es el Mercado común, la caracterización de este tipo es excesivamente dependiente del Derecho comunitario, al ser la Unión Europea la única integración que ha perfeccionado el tipo. Son relevantes también dos Uniones Aduaneras que se dirigen a crear el Mercado común, como MERCOSUR ${ }^{11} \mathrm{y}$, en mayor, medida la Comunidad Andina de Naciones ${ }^{12}$, pese a sus continuos avances y retrocesos en el proceso de integración; aunque ambas no han dejado de inspirarse en el ejemplo europeo.

El Mercado común exige haber perfeccionado completamente los tipos de Zona de libre comercio y Unión aduanera, algo que frente a lo que generalizadamente se supone no se logró hasta principios de los años noventa del siglo pasado en la Unión Europea. La unidad económica nacional y su correlato, la unidad de mercado ${ }^{13}$, en un Estado es sustituida por la unidad de mer-

precisar que, recientemente, Bolivia, que forma parte de la Comunidad Andina de Naciones (CAN), ha solicitado su ingreso en MERCOSUR (lo que está pendiente sólo de la ratificación por parte del Parlamento brasileño); y la CAN, a través de sus órganos ejecutivos, ha autorizado a este Estado a formar parte simultáneamente de dos Uniones aduaneras. La situación se debe considerar excepcional y fruto del proceso de avances y retrocesos de la CAN, que con esta medida quiebra su Unión aduanera, y de que MERCOSUR no haya consolidado todavía su Unión aduanera.

11 Véase GLITZ, Frederico E. Z., «Los 25 años del MERCOSUR y las perspectivas jurídicas del proceso de integración sudamericana», en Constitucionalizando la globalización, ob. cit., pp. 369 y ss.

${ }^{12}$ Véase CONTIPELLI, Ernani, «Comunidad Andina de Naciones», en Constitucionalizando la globalización, ob. cit., pp. 281 y ss.

13 Sobre la unidad de mercado véase DE LA QUADRA-SALCEDO JANINI, Tomás, Unidad económica y descentralización política, Tirant Lo Blanch, Valencia, 2004; y del 
cado en el ámbito territorial que se corresponde con la integración. La unidad de mercado implica la libre circulación de mercancías, servicios, capitales y trabajadores y la igualdad en las condiciones básicas de ejercicio de la actividad económica. Luego a la libre circulación de bienes y servicios debe añadirse la de trabajadores y la de capitales. No se suele discutir que hay también igualdad en las condiciones básicas de ejercicio de la actividad económica; sin embargo, habría que definir con mayor precisión qué se entiende por estas condiciones básicas porque aquí se albergan serias dudas de que el requisito se haya alcanzado en ningún lugar, porque las desigualdades en el impuesto de sociedades, en los salarios y, especialmente, en los costes de financiación de las empresas hacen dudar seriamente de que esa igualdad se haya alcanzado en la Unión Europea, al punto de poderse afirmar que hay una igualdad en las condiciones básicas de ejercicio.

La política comercial queda completamente en manos de los órganos de gobierno del Mercado común, igual que en la Unión aduanera, como se acaba de indicar. La política monetaria sufre restricciones más intensas. En esta fase de integración se fija una banda estrecha de fluctuación del valor de las divisas para evitar mayores oscilaciones, con lo que una hipotética devaluación de una de ellas requeriría la aquiescencia del órgano ejecutivo de la integración. En consecuencia, se exige también una coordinación de la política fiscal, por lo que los márgenes para políticas macroeconómicas estatales quedan bastante reducidos.

Suele reforzarse la economía de mercado, en cuanto economía descentralizada y desconcentrada ${ }^{14}$, en esta última vertiente se intensifican los instrumentos de defensa de la competencia ${ }^{15}$. Este refuerzo de la economía de mercando es constatable no sólo por la experiencia europea, sino porque la propia globalización la reclama y desarrolla. Otro tanto puede decirse en relación con la propiedad privada y la libertad de empresa; la posibilidad de

mismo autor, Mercado nacional único y Constitución, Centro de Estudios constitucionales, 2008, así como la STC 88/1986, FJ 6. También CIDONCHA MARTÍN, Antonio, «El Tribunal Constitucional y la Ley de Garantía de la Unidad de Mercado. Comentario a la STC 79/2017, de 22 de junio de 2017», Revista Española de Derecho Constitucional, n. ${ }^{\circ} 114$, pp. 301 y ss.

14 ASENJO, Óscar de Juan, La Constitución económica española, Centro de Estudios Constitucionales, Madrid, 1984, pp. 144-149, defiende que la esencia de la economía de mercado radica en ser un estilo de economía donde el poder económico se encuentra descentralizado y desconcentrado. En el mismo sentido, GARCÍA ECHEVARRÍA, Santiago, El orden económico en la Constitución, Asociación de Estudios Empresariales, 1978, pp. 35-40.

${ }^{15}$ FONT GALÁN, Juan Ignacio, Constitución económica y Derecho de la competencia, Tecnos, Madrid, 1987, p. 166, señala: «La competencia es [...] el auténtico instrumento realizador (o, si se quiere, 'el motor') del sistema de economía de mercado». 
imponer limitaciones a ésta, connaturales en una constitución económica intervencionista, es más reducida. Esta realidad explica las acusaciones de que la globalización está siendo construida sobre bases liberales o, incluso, ultraliberales.

Todo este amplio conjunto de medidas requiere de una implementación normativa que da lugar, probablemente, al elemento más distintivo de la fase de integración que denominamos Mercado común: la creación de un nuevo ordenamiento jurídico que debe relacionarse con los estatales conforme al principio de competencia ${ }^{16}$, aunque hay quien defiende que la relación es conforme al principio de jerarquía ${ }^{17} \mathrm{o}$, en posiciones doctrinales menos extremas, de primacía ${ }^{18} \mathrm{o}$ atribución ${ }^{19}$. Se está en presencia de una estructura constitucional desde una perspectiva material, aunque no formal. Las normas que encabezan el ordenamiento, Derecho primario, no poseen las características propias de cualquier norma constitucional: no son creación de un poder constituyente, no son producidas mediante procedimientos que permitan expresar un mayor plus de legitimidad democrática, como son los quórums elevados o la ratificación de las decisiones de los representantes por los ciudadanos

${ }^{16}$ GARCÍA GUERRERO, José Luis, La publicidad. Fundamentos y límites constitucionales, Tirant Lo Blanch, Valencia, 2014, pp. 150-152 y las correspondientes notas a pie de página, afirmación realizada a propósito del ordenamiento de la Unión Europea.

17 LOPPZ CASTILLO, Antonio, SAINZ ARNAIZ, Alejandro, y FERRERES COMELLA, Víctor, Constitución española y Constitución europea: Análisis de la Declaración del Tribunal Constitucional (DTC-1/2004, de 13 de diciembre), Centro de Estudios Políticos y Constitucionales, Madrid, 2005, en posiciones cercanas al principio de jerarquía, también en relación con la Unión Europea.

${ }_{18}$ Sentencia del Tribunal de Justicia de las Comunidades Europeas de 15.07.1964, Asunto 6/64, Costa/Enel. La argumentación de la sentencia del Tribunal descansa en la propia naturaleza del derecho de la Unión; la idea básica consiste en que una vez que los Estados miembros han cedido parte de sus competencias a la Unión, la actuación de ésta ha de ser uniforme y no puede verse condicionada o limitada por una norma o decisión de uno de ellos. Esta sentencia, además, señala: «[...] a diferencia de los Tratados internacionales ordinarios, el Tratado de la CEE ha instituido un ordenamiento jurídico propio integrado en el sistema jurídico de los estados miembros, desde la entrada en vigor del tratado [...]». Pese a las reticencias de los Tribunales Constitucionales alemán e italiano, el Tribunal de Justicia insiste en la primacía del derecho de la Unión sobre las normas constitucionales, véase la Sentencia de 15.01.2013, Asunto C-416/10 Krizan e.a. versus Slovens$k a$, apartado 70 .

19 Diversos preceptos del Tratado de la Unión Europea reiteran, de forma especialmente significativa, el principio de atribución. Entre todos destaca el artículo 5 cuando dispone: «1. La delimitación de competencias de la Unión se rige por el principio de atribución...2. En virtud del principio de atribución, la Unión actúa dentro de los límites de las competencias que le atribuyen los Estados miembros en los Tratados para lograr los objetivos que éstos determinan. Toda competencia no atribuida a la Unión en los Tratados corresponde a los Estados miembros». 
mediante referéndum, y tampoco expresan pluralismo político, por lo que no admiten desarrollos diversificados según la orientación ideológica del creador de la norma ${ }^{20}$. Tras el Derecho primario del Mercado común se sitúa el Derecho derivado, que se relaciona con el primero mediante el principio de jerarquía normativa. Este Derecho derivado se encabeza con normas de rango legal de naturaleza muy diferente. Al frente del Derecho derivado coexisten normas de rango legal, que exigen la implementación por parte de los órganos legislativos de los Estados integrados, junto con otras disposiciones legales que son de aplicación directa en todos los Estados. Las primeras son las propias de una confederación, mientras que las segundas son propias de un Estado federal. La producción de este complejo normativo exige la creación de un Parlamento y de un Gobierno del Mercado común, que se complementa, siguiendo la clásica división del poder, con un Tribunal que tiene la última palabra en la interpretación y aplicación del ordenamiento comunitario. La creación de estos órganos supraestatales exige la cesión por parte de los Estados de competencias soberanas de naturaleza legislativa, ejecutiva y judicial, lo que obliga a incluir en las constituciones de los Estados cláusulas constitucionales de integración ${ }^{21}$.

La intensidad en la producción de normas por el Mercado común ${ }^{22}$ no se limita al campo económico. La efectividad del desarrollo de las normas económicas exige extenderlas a otros sectores del ordenamiento aparentemente distantes, homologación de títulos para el ejercicio profesional, control de fronteras y política de inmigración, creación de partidos políticos. Se puede

${ }^{20}$ La STC 11/1981, FJ 7, establece que la Constitución se presenta como un «marco de coincidencias lo suficientemente amplio como para que dentro de él quepan opciones políticas de muy diferente signo». En la literatura jurídica véase HESSE, Konrad, Escritos de Derecho Constitucional, Centro de Estudios Constitucionales, Madrid, 1992, pp. 33 y ss.; BÖCKENFÖRDE Ernst Wolfgang, «Los métodos de interpretación constitucional. Inventario y crítica», en el libro Escritos sobres Derechos fundamentales, Nomos Verlagsgesellschaft, Baden-Baden, 1993, p. 17; AGUILÓ REGLA, Josep, «Sobre el constitucionalismo y la resistencia constitucional», DOXA: Cuadernos de Filosofía del Derecho, n. ${ }^{\circ} 26,2003$, pp. 32-34, con el que compartimos que algunas normas de la Constitución son cerradas. También sobre el carácter abierto de las normas constitucionales, SCHNEIDER, Juan-P., «Continencia judicial y estructura normativa abierta del Derecho Constitucional», en el libro dirigido por LÓPEZ PINA, Antonio, División de poderes e interpretación (hacia una teoría de la praxis constitucional, Tecnos, Madrid, 1987, pp. 75 y 76.

${ }^{21}$ Sobre la cláusula de integración en la Unión Europea véase a GARCÍA VICTORIA, Ignacio, «Unidad Económica supraestatal», en el libro Constitucionalizando la Globalización, ob. cit., pp. 237 y ss.

${ }_{22}$ Véase con mayor detalle a GONZÁLEZ JIMÉNEZ, Magdalena, «Esbozo de una teoría general del Mercado común como modalidad de integración económica», en el libro Constitucionalizando la Globalización, ob. cit., pp. 187 y ss. 
considerar que cerca de un setenta por ciento de las normas de los Estados que se integran en un Mercado común proviene de órganos ejecutivos y legislativos de este ámbito territorial.

La creación de esta compleja estructura constitucional desde una perspectiva material lleva, finalmente, a adoptar buena parte de los principios que estructuran un Estado federal, como el de unidad, pluralismo, lealtad y solidaridad. Las relaciones en su seno se desarrollan conforma a los principios de supra y subordinación, coordinación e inordenación ${ }^{23}$.

El cuarto tipo de integración económica es la Unidad económica y monetaria supraestatal ${ }^{24}$. En esta fase el objetivo económico queda claramente superado, se han cumplido con creces los objetivos que persigue la globalización a través del multilateralismo o de las integraciones. La unidad económica debe coincidir con un proyecto político común de los Estados que forman la integración. Se requiere haber completado perfectamente las fases precedentes de Zona de libre comercio, Unión Aduanera y Mercado común.

El elemento más relevante de esta fase de integración supone la creación de una moneda común, con la consecuente desaparición de las divisas de los Estados integrados. La política monetaria se transfiere completamente a la integración, lo que implica la creación de un Banco central para ejercitar esta política, así como la supervisión de las entidades financieras. Con carácter previo a la creación de la moneda es necesaria una convergencia de la inflación, el déficit y la deuda pública. La última palabra sobre la política fiscal queda en manos de los órganos de la integración. El resultado es que éstos deciden la totalidad de la política comercial, monetaria, y dejan escaso margen a la política fiscal ${ }^{25}$. Ésta en su vertiente de ingresos pierde los impuestos indirectos sobre el consumo y debería perder el impuesto de sociedades. La vertiente de gastos queda condicionada a las trazas maestras fijadas por la integración que se reserva, además, un control sobre la aprobación de los presupuestos estatales en casos de incumplimiento de los objetivos fijados.

La integración tiene la totalidad de las competencias en política comercial y monetaria y también buena parte de la política fiscal por lo que difícilmente

${ }^{23}$ Véase GARCÍA PELAYO, Manuel, Derecho Constitucional Comparado, Alianza Editorial, Madrid, 1984, pp. 233-240, que utiliza estos principios para explicar las relaciones jurídicas en las estructuras constitucionales complejas, como el Estado federal.

${ }^{24}$ Una investigación más detallada en MEIX CERECEDA, Pablo, «La Unidad Económica y Monetaria supraestatal», en el libro Constitucionalizando la Globalización, ob. cit., pp. 251 y ss.

${ }_{25}$ Sobre las consecuencias de transferir la política monetaria véase también a MENÉNDEZ MENÉNDEZ, Agustín, «Integración económica e integración política», en el libro dirigido por LÓPEZ CASTILLO, Antonio, Instituciones y Derecho de la Unión Europea, vol. I, Tirant Lo Blanch, Valencia, 2015, p. 139. 
puede sostenerse que no tenga también la competencia de la política macroeconómica.

Ante esta realidad, aquí se va a sostener, en línea con numerosos estudios de economistas ${ }^{26}$, la necesidad de que en esta fase la integración emita la mayor parte de la deuda pública y prevea instrumentos de apoyo a la que quede en manos de los Estados (la deuda es insostenible sin el respaldo de un Banco central), intensifique los mecanismos de solidaridad (imprescindible en cualquier estructura constitucional), que responda de los depósitos bancarios de los ciudadanos de la integración (a su Banco central corresponde la supervisión de las entidades financieras) y del subsidio de desempleo (dado su peso en la política macroeconómica). En consecuencia, la integración debe asumir su propia política fiscal, en la vertiente de ingresos a través de los impuestos al consumo y a las sociedades mercantiles, y en la vertiente de gastos aprobando unos presupuestos anuales propios. La política exterior y la de defensa debe estar en manos de la integración, la primera por su interrelación con la política comercial y la segunda porque es la única forma de respaldar a la primera; lo que, a su vez, arrastra al control de fronteras y a la inmigración. Aparece un Estatuto de ciudadanía de la integración con sus correspondientes derechos y deberes. Aproximadamente, más de dos tercios de la política legislativa es producida directamente o a través de implementación por la integración. Las competencias que quedan en manos de los Estados deben coordinarse a través de los órganos de integración. La integración resultante es un Estado federal materialmente, aunque no lo sea formalmente, por lo que aquí se defiende que debe dotarse de una estructura federal que responda al concepto racional normativo de Constitución.

La Unión Europea es la que más se ha aproximado a esta fase de integración, pero todavía está distante respecto a su perfeccionamiento. Se recuerda que los órganos de la integración ni siguiera en esta fase han conseguido una igualdad en las condiciones básicas de ejercicio de la actividad económica. Para lograrla y para perfeccionar esta fase, en línea con lo reseñado en el párrafo anterior, es probable que sea necesario que el grueso de la deuda pública esté en su mayor parte en manos de la Unión, que responda de los depósitos bancarios de la zona euro, que absorba la competencia en el impuesto de sociedades procediendo a una uniformidad de tipos de gravamen, y en el impuesto sobre el consumo, que apruebe anualmente unos

26 KRUGMAN, Paul y DE LA DEHESA, Guillermo, Economic and Monetary Unions and the Regions, Group of Thirty, 1995, pp. 43 y ss. Consultado el 27/03/2019 en: http://group30.org/images/uploads/publications/G30_EMUandRegions.pdf. En la misma línea, aunque con un claro carácter contrario a la moneda única, se pronuncia el también Nobel STIGLITZ, Joseph E., junto a SEN, Amartya y FITOUSSI, Jean-Paul, Mismeasuring Our Lives: Why GDP Doesn't Add Up, The New Press, 2010. 
presupuestos generales de una cierta entidad, y que responda, también, del subsidio de desempleo. Otro tanto cabría decir respecto a la política exterior, de defensa, control de fronteras e inmigración ${ }^{27}$. Se estima también que el ordenamiento de la Unión debe recoger toda la regulación necesaria y abandonar los instrumentos intergubernamentales, que hasta ahora ha utilizado predominantemente al desarrollarse el proceso de construcción a varias velocidades, lo que no implica per se la eliminación de diversos ritmos en la integración, que atendiendo a la diversidad imperante en la Unión Europea es actualmente, probablemente, inevitable. Finalmente, y como corolario, es necesaria la elaboración y aprobación de una Constitución federal.

\section{La segunda etapa: Los acuerdos comerciales en que una parte, al menos, es una integración económica}

En la primera aproximación a esta materia en $2005^{28}$ se pensaba que hasta aquí llegaba la globalización, es decir, que la tendencia de las empresas y los mercados en superar el marco estatal iba a quedar satisfecha con integraciones económicas supraestatales cada vez más intensas. No obstante, en $2013^{29}$ ya se pudo afirmar que ésta era la primera etapa de la globalización, pero hay una segunda caracterizada porque en estos nuevos acuerdos una de las partes, al menos, debe ser una integración económica y es el ejecutivo de la misma quien firma el nuevo acuerdo comercial. Hasta ahora, éstos se han limitado a Acuerdos de libre comercio, esto es, al primer tipo de integración de la primera fase. No obstante, habrá que estudiar con detenimiento estos nuevos acuerdos porque hay quien ha extraído consecuencias equivocadas al estimar que son un nuevo tipo, ya que presentan elementos novedosos, que, sin embargo, en realidad, siempre han estado presentes en la política comercial de los Estados Unidos, como la creación de un órgano más o menos ejecutivo, la intensa implementación normativa que exigen y la creación de

${ }^{27}$ COMISIÓN EUROPEA, Documento de reflexión sobre el futuro de las finanzas de la UE, 2017, p. 22. Consultado el 27/03/2019 en: https://ec.europa.eu/commission/sites/ beta-political/files/reflection-paper-eu-finances_es.pdf

${ }^{28}$ GARCÍA GUERRERO, José Luis, «Integración económica y reforma constitucional», en el libro colectivo: Visión y análisis comparativo de reformas constitucionales en Iberoamérica, ONU, PUND, Santo Domingo, 2005, pp. 135-155.

${ }^{29}$ GARCÍA GUERRERO, José Luis, «Las integraciones económicas supraestatales y los acuerdos entre bloques económicos, en definitiva, la globalización como último embate al concepto racional normativo de Constitución», en el libro Constitución, Justicia constitucional y Derecho procesal constitucional (Liber Amicorum en Homenaje al profesor Dr. Juan Manuel Pellerano Gómez), coordinado por JORGE PRATS, Eduardo y VALERIO JIMENIÁN, Manuel, Instituto Dominicano de Derecho Constitucional y Librería Jurídica Internacional, Santo Domingo, República Dominicana, 2014, pp. 544-591. 
órganos arbitrales o judiciales. Cuestión esta última que levantó una especial polémica en Europa con ocasión de la negociación del Acuerdo Transatlántico de comercio e inversiones entre la Unión Europea y Estados Unidos $(\text { TTIP })^{30}$, interrumpida tras la llegada de Trump a la Casa Blanca.

Es razonable pensar que estas integraciones de la segunda etapa de la globalización se intensifiquen en el futuro y pasen a los siguientes tipos: Unión aduanera, Mercado común, y Unidad económica y monetaria supraestatal. El límite que pueda alcanzar la globalización y sus acuerdos de integración no puede vislumbrarse hoy con seguridad, pero no cabe descartar que, en el largo plazo, se pretenda alcanzar la unidad económica mundial. Ahora bien, debe advertirse que pasar de Unión aduanera a Mercado común no es tarea fácil, ni siquiera en la primera etapa de la globalización, fundamentalmente porque exige una cierta infraestructura monetaria, lo que explica que este objetivo sólo se haya alcanzado en Europa, fracasara en su día en el Pacto Andino y no se haya conseguido todavía en MERCOSUR.

\section{EL EMBATE DE LA GLOBALIZACIÓN A LA DISTRIBUCIÓN TERRITORIAL DEL PODER}

La forma de Estado desde la perspectiva de la distribución territorial del poder ha conocido históricamente el Estado unitario y el Estado compuesto. La primera forma de éste fue el confederal, posteriormente se desarrollaron el federal, el regional y el autonómico ${ }^{31}$. Estas dos últimas han sido una aportación a la ciencia constitucional mundial por parte de la española.

Se ha demostrado históricamente que la forma confederal desemboca en una disgregación del Estado o en su transformación en unitario. La forma confederal nació en los Estados Unidos de América con la independencia de las colonias americanas y sobrevivió con dificultades hasta la aparición, pocos años después, del Estado federal estadounidense ${ }^{32}$. El Estado regional fue creado por la Segunda República española como tertium genus entre el Estado federal y el unitario para tratar de afrontar las reivindicaciones de los nacionalismos periféricos españoles y otro tanto sucedió con el Estado

${ }^{30}$ Véase TAIBO, Carlos, Para entender el TIPP (Una visión crítica del Acuerdo Transatlántico de comercio e inversiones), Catarata, Madrid, 2016.

${ }^{31}$ En esta materia es de obligada consulta SOLOZABAL ECHAVARRIA, Juan José, Bases constitucionales del Estado autonómico, McGraw-Hill, Madrid, 1988; Nación y Constitución: soberanía y autonomía en la forma política, Biblioteca Nueva, 2004; y Tiempo de reformas: el Estado autonómico en cuestión, Biblioteca Nueva, 2006. También AJA FERNÁNDEZ, Eliseo, El Estado autonómico: federalismo y hechos diferenciales, Alianza Editorial, Madrid, 1999.

32 Véase GARCÍA PELAYO, Manuel, Derecho Constitucional Comparado, Alianza Editorial, Madrid, 1984, pp. 325 y ss. 
autonómico, tras la aprobación de la Constitución española de 1978. Éste, tras su construcción básicamente jurisprudencial ${ }^{33}$, no difiere sustancialmente de los Estados federales más descentralizados del mundo ${ }^{34} \mathrm{e}$, incluso, el País Vasco puede considerarse el ente territorial periférico con más autonomía política del mundo.

La globalización no afecta a la distribución territorial del poder de un Estado unitario en la medida en que todas las competencias pertenecen al poder central. Por el contrario, origina un embate, de intensidad variable, a todos los Estados compuestos, concreta y específicamente, a su ámbito competencial, a la autonomía política de los entes territoriales periféricos y al Estado social, especialmente en materia educativa y sanitaria.

El estudio de este embate es de intensidad variable, como se acaba de decir, por lo que sus consecuencias obligarían, a diferenciar, de una parte, entre las dos vertientes de la globalización (multilateral y bilateral), los distintos tipos de integración y entre las dos etapas o fases de las integraciones; $\mathrm{y}$, de otra, exigirían distinguir entre los diferentes Estados compuestos y dentro de cada uno de ellos entre las concretas aplicaciones que se han hecho por cada Estado. Al no ser posible aquí abarcar este ámbito, el trabajo se acotará, de un lado, al Estado autonómico español y, de otro, a la Unión Europea. No obstante, la detección de los problemas en el Estado autonómico permite al lector avezado trasladarlos mutatis mutandis a cualquier otra forma de Estado compuesto en su concreta aplicación. La referencia a la Unión Europea viene dada por la pertenencia de España a esta integración y por tratarse de la única que está construyendo el cuarto tipo de integración de la primera etapa de la globalización: la Unidad económica y monetaria supraestatal. Sin embargo, ello no impedirá analizar otros embates originados por el multilateralismo, por otros tipos de integraciones o por la segunda etapa de éstas cuando el ámbito material afectado lo permita.

\section{AL ÁMBITO COMPETENCIAL DE LAS COMUNIDADES AUTÓNOMAS SEGÚN SE INTENSIFICA LA INTEGRACIÓN}

En cualquier Estado compuesto se reconoce el pluralismo territorial, lo que conlleva aceptar que los entes territoriales periféricos ostentan autonomía política. Su ejercicio implica potestades ejecutivas y legislativas, lo que

${ }^{33}$ FERNÁNDEZ FARRERES, Germán, La contribución del Tribunal Constitucional al Estado Autonómico, Iustel, 2005.

${ }^{34}$ Véase GARCÍA GUERRERO, José Luis, «Lo Stato autonómico, evoluzione e e qualche conclusione dopo la prima reforma integrale si alcuni statuti», en el libro Regionalismi e Statuti (Le riforme in Spagna e in Italia), dirigido por GAMBINO, Silvio, Giuffrè, Milano, 2008, p. 293. 
supone la aparición de ordenamientos territoriales, subordenamientos en el caso autonómico, que se relacionan con el poder central conforme al principio de competencia. Si se sigue a García Pelayo, el Estado autonómico daría lugar, como en cualquier Estado compuesto, a la aparición de relaciones jurídicas de coordinación, supra y subordinación, e inordenación ${ }^{35}$. La existencia de este Estado, que reconoce el pluralismo territorial, exige una cierta tensión entre los principios de uniformidad y diversidad. Si se impone el primero, este tipo de Estado deriva en un unitario; si lo hace el segundo, el proceso desemboca en la disgregación del mismo. En consecuencia, el sistema conlleva una tensión permanente que genera conflictos políticos y competenciales. Los primeros deben resolverse en una cámara de representación territorial, no cabe un Estado intensamente descentralizado sin esta segunda asamblea. Precisamente aquí residen parte de los problemas centrífugos del Estado español; el Senado no es una cámara auténtica de representación territorial y esa función la cumple el Congreso de los Diputados, lo que origina graves distorsiones en su función: la representación del pueblo español. Los segundos, los conflictos competenciales, agotada la vía política, deben resolverse, en última instancia, por un órgano jurisdiccional, el Tribunal Constitucional en el caso español, como es propio de cualquier Estado Constitucional de Derecho, que al integrarse en la estructura constitucional del poder central es manifestación de la subordinación (relaciones de supra y subordinación) del poder periférico a éste.

La manifestación por excelencia de las relaciones de coordinación es la distribución competencial entre el poder central y los entes territoriales autonómicos, lo que significa que en ciertos ámbitos materiales hay un parlamento central que aprueba leyes que obligan a todos los ciudadanos españoles y en otros existen parlamentos autonómicos que dicta leyes que sólo vinculan en el ámbito de su comunidad autónoma. Es en esta esfera de la distribución competencial donde la globalización origina el embate más relevante, dependiendo su intensidad de las categorías que se han discernido dentro de una teoría general de la globalización, como, a continuación, se va a poder apreciar.

Si se analiza la vertiente multilateral, se puede apreciar que la liberalización de mercancías afecta levemente a ámbitos competenciales que corresponden a las autonomías. La agricultura, la ganadería o los aprovechamientos forestales son materias tradicionalmente atribuidas a los entes territoriales periféricos y así sucede en el caso de las comunidades autónomas en España, como dispone el artículo $148.7^{\mathrm{a}}$ y $8^{\mathrm{a}} \mathrm{CE}$. La afección se produce porque las decisiones regulatorias se adoptan en la OMC y ante este organismo sólo hay

${ }^{35}$ Derecho Constitucional Comparado, ob. cit., pp. 233 y ss. 
representación por parte del gobierno español que se encuentra, además, limitado por la presencia también en esta institución de la Unión Europea, que expresa la posición consensuada en este ámbito territorial y persigue llegar a acuerdos con los demás Estados o integraciones allí representados.

La afección del multilateralismo a las competencias autonómicas en este ámbito se estima ${ }^{36}$ muy escasa porque los tres ámbitos materiales reseñados son especialmente sensibles, como lo prueba la existencia del Comité de Agricultura de OMC, y no han dado lugar a avances de liberalización multilateral de suficiente entidad como para afectar a las competencias de las autonomías. Además, la garantía de la unidad de $\operatorname{mercado}^{37}$ por el poder central y europeo absorbe la mayor parte de las regulaciones que pudieran incidir en la esfera autonómica. Otro tanto sucede con los Acuerdos preferenciales de comercio, que, por la sensibilidad de estas materias, ligadas a otros imperativos constitucionales (pleno empleo, desigualdad entre territorios, adecuada distribución de la población en el territorio), excepcionan o someten a cláusulas de protección estas esferas competenciales; al tiempo que en las restantes pretenden intensificar el tráfico de mercancías o sentar las bases de futuros Acuerdos de libre comercio.

El embate adquiere consistencia cuando se firma el Acuerdo de libre comercio, que implica la libre circulación de mercancías, algunos servicios, y más recientemente, inversiones y propiedad intelectual. La circulación de servicios, en principio, y la protección de inversiones no afectaría a la competencia autonómica, pero si podría hacerlo la salvaguardia de la propiedad intelectual (ésta en la globalización integra, además, buena parte de la garantía de la innovación tecnológica), que, en algunos casos, obligaría a adoptar medidas normativas y ejecutivas en orden a su protección. No obstante, el gran embate se produce en el ámbito competencial, como se ha señalado, a modo de ejemplo, en agricultura, ganadería o aprovechamientos forestales. Garantizar la libre circulación de todas estas mercancías obliga a dictar toda una serie de normas por los órganos de la integración que son aplicadas por órganos arbitrales o, en el mejor de los casos, jurisdiccionales. Y aquí reside el problema, los órganos de la integración asumen competencias del legislativo y ejecutivo autonómico (leyes y reglamentos) en todas las medidas normativas que tengan que dictar para asegurar la libre circulación. En estos órganos ejecutivos de la integración sólo está representado el gobierno del

${ }^{36}$ Sólo un estudio capilar del ordenamiento OMC, Unión Europea, estatal y autonómico podría permitir comprobar las afecciones concretas a este último. Obviamente, una investigación de esa profundidad debería ser específica y no puede afrontarse en este capítulo; por lo que en esta ocasión y en las sucesivas nos moveremos en el ámbito de las meras estimaciones.

37 Véase supra nota 10. 
poder central, con lo que al parlamento y al gobierno autonómico sólo les queda, en el caso español, la posibilidad de influir (al primero indirectamente) a través de las conferencias sectoriales o, incluso, con más intensidad, en las comisiones bilaterales. En consecuencia, resultan afectadas las relaciones de coordinación (competencias) entre el poder central y el autonómico y otro tanto sucede en las relaciones de inordenación, esto es, la contribución del poder territorial a la conformación de la voluntad estatal.

En el segundo tipo de integración, en la Unión aduanera, sus órganos ejecutivos, donde están presentes los ejecutivos de los Estados integrados, fijan unos aranceles comunes frente al exterior, así como contingentes de importación. Esto no supone un incremento sustancial del embate al principio de coordinación, pero sí al de inordenación. El Estado autonómico prevé mecanismos a través de los cuales el ente territorial contribuye con los demás a conformar la voluntad estatal que fija los contingentes y los aranceles. Éstos pueden ser muy importantes, incluso, decisivos, para la agricultura, la ganadería o los aprovechamientos forestales de una determinada comunidad autónoma. Este problema constitucional se resuelve a través de las conferencias sectoriales, que reúnen al ministro del ramo con los respectivos consejeros autonómicos (la competencia parlamentaria se salvaguarda por las instrucciones que trasmiten a éstos). El sistema se resiente cuando por mor de la Unión aduanera el ministro nacional debe consensuar esos aranceles y contingentes con los de los otros Estados.

El problema se agrava en el tercer tipo de integración, el Mercado común. Su unidad de mercado y las consecuentes libertades de circulación de mercancías, servicios, capitales y mano de obra; la aparición de poderes legislativos, ejecutivos y judiciales; y la consecuente inserción del ordenamiento del poder central en el de la integración llevan a transferir los ámbitos competenciales referidos a la integración. La legislación en la materia corresponderá al Consejo y al Parlamento Europeo en el caso de la Unión. El legislativo y el ejecutivo autonómico pierden estas competencias. Ha quedado completamente afectado el principio de coordinación, así como el de inordenación, que sólo podrá atenuarse en su embate, muy parcialmente, si se prevén mecanismos para que la posición del ejecutivo nacional, de cara a las negociaciones con los demás Estados miembros, se conforme en la correspondiente conferencia sectorial o en una comisión bilateral. La afección también puede atenuarse si se prevé la integración en la delegación estatal de representantes de la comunidad autónoma cuando la regulación europea le resulte vital. Esta atenuación del embate es posible respecto a la posición del Consejo Europeo. Queda abierto el fleco del Parlamento europeo sin que aquí se atisbe otra posibilidad que la de implementar mecanismos de relación entre el parlamento y el ejecutivo autonómico con los europarlamentarios estatales o con algunos de éstos. 
El cuarto y último tipo de integración, la Unidad económica y monetaria supraestatal, se estima que todavía no se ha perfeccionado en el único lugar del mundo en que se está construyendo: la Unión Europea. Se cree que no origina, en principio, mayores ataques a los principios de coordinación y inordenación, más allá de que supone que se ha perfeccionado el tipo de Mercado común.

Por el contrario, la segunda etapa de las integraciones viene a suponer la destrucción completa de las relaciones de coordinación e inordenación. Esta fase o etapa, como se ha visto, supone que la Unión Europea firme un Acuerdo de libre comercio con otro Estado o con otra integración. Desde una perspectiva constitucional, ello supone multiplicar por tres el embate a las relaciones jurídicas de coordinación e inordenación. Éstas funcionan cuando hay una relación directa entre la autonomía y el poder central; cuando las competencias se trasladan a la Unión Europea (lo que ya sucede en el tipo Mercado común) esto significa que, como regla general, no hay relación directa entre el ente regional y el supraestatal y que el único contacto puede realizarse, indirectamente, a través de la intermediación del poder central. Y en lo que aquí interesa, estas relaciones jurídicas desaparecen cuando se trata de establecer una relación con los órganos de la integración de la segunda etapa (el acuerdo de la Unión con otro Estado o integración) porque en este caso hay dos grados de intermediación, dos instancias de poder, entre el ente regional y la integración de la segunda etapa, concretamente el estatal y el europeo. En este último caso, en la segunda fase de las integraciones, es el propio poder central el que se sitúa en la misma posición que tiene el ente regional cuando se crea un Mercado común, esto es, entre el Estado y el Acuerdo de integración se coloca como instancia intermedia la Unión Europea. En conclusión, se puede extraer como regla que los embates de las integraciones se doblan, como mínimo, cada vez que en la relación entre dos poderes se interpone otra instancia de poder. En estos casos suele haber, además, una transferencia de competencias del poder legislativo al ejecutivo.

\section{A SU AUTONOMÍA POLÍTICA (FINANCIERA)}

\section{A propósito de la soberanía}

Desde hace tiempo se viene sosteniendo que la globalización supone un embate a la soberanía que se intensifica a medida que se profundiza en el multilateralismo o en el bilateralismo (integraciones). Previamente, Rodrik ya había formulado su trilema sobre cómo es imposible incrementar dos de las tres siguientes variables: integración, soberanía, democracia ${ }^{38}$. El éxito

${ }^{38}$ RODRIK, Dani, La paradoja de la globalización (Democracia y el futuro de la economía mundial), Antoni Bosch, Barcelona, 2011. RUBIO LLORENTE, Francisco, 
universal de su trabajo cercena cualquier duda al respecto. No obstante, hay quien ha venido relativizando la utilidad del concepto soberanía ${ }^{39}$ y extrayendo como consecuencia la irrelevancia de su pérdida. Se estima que esta posición es errónea. Aunque se admitiera la poca relevancia de la soberanía, seguiría siendo cierto lo que en último extremo significa: el derecho universal de los ciudadanos a tomar las decisiones del gobierno de su comunidad.

En el multilateralismo y en los tipos de integración Acuerdo de libre comercio o Unión aduanera es factible admitir la regla de la soberanía compartida ${ }^{40}$ gracias a que en el multilateralismo cada Estado toma su decisión autónomamente y en los dos primeros tipos de integración funciona la regla de la unanimidad entre los ejecutivos de los Estados miembros. Al fin y al cabo, es cierto, que la soberanía tiene un plano interno: poder supremo, absoluto indivisible e irresistible; pero tiene también uno externo que se manifiesta en el ámbito internacional en que las relaciones con los demás Estados se mantienen conforme al principio de igualdad. La regla de la unanimidad y el plano externo de la soberanía parecen pues salvar su núcleo más intenso. Esta fórmula no sería suficiente para sostener la soberanía del Estado en el tipo Mercado común. Así, en el caso de la Unión Europea se requeriría además una colegislación en todos los ámbitos materiales entre el Parlamento Europeo y el Consejo; además, este último debería configurarse como cámara de representación territorial, funcionando al modo de los Congresos o Dietas de los Estados confederales ${ }^{41}$. En el tipo de Unidad económica y monetaria supraestatal, la unanimidad en la toma de decisiones se ha visto sustituida por la mayoría cualificada y, a veces, incluso, por la minoría cualificada. No puede por menos que reconocerse que se ha transferido ámbitos soberanos de tal entidad que podría afirmarse, quizá, que hay más soberanía

«Globalización económica y reforma constitucional», Revista de Occidente, n. ${ }^{\circ} 388$, 2013, pp. 5-9, en su discurso de investidura como doctor honoris causa por la Universidad de Valladolid, llamó la atención sobre el trabajo de Rodrik e incluyó a la globalización como uno de los tres grandes problemas del Derecho Constitucional español.

39 HELLER, La soberanía, Universidad Nacional Autónoma de México, México DF, 1965. WYDUCKEL, D., «La soberanía en la historia de la dogmática alemana», Fundamentos. Cuadernos monográficos de Teoría del Estado, Derecho Público e Historia Constitucional, n. ${ }^{\circ}$ 1, monográfico sobre «Soberanía y Constitución», Junta General del Principado de Asturias, 1998. Un análisis de la soberanía en el contexto de la globalización en KRASNER, Stephen D., Soberanía: Hipocresía organizada, Paidós, 2001. SASSEN, Saskia, ¿Perdiendo el control? La soberanía en la era de la globalización, Barcelona, Bellaterra, 2001.

${ }^{40}$ El término «soberanía compartida» ha disfrutado de gran predicamento en la Unión Europea para explicar su déficit democrático. Ha sido utilizado también reiteradamente en España como forma de superar el contencioso con el Reino Unido en relación con Gibraltar.

${ }^{41}$ GARCÍA PELAYO, Manuel, Derecho Constitucional Comparado, ob. cit., pp. 213-214. 
en la Unión que en los Estados miembros. En la segunda etapa de la globalización el ejercicio de la soberanía corresponde a la Unión, los Estados quedan en la misma posición que una comunidad autónoma respecto a la integración europea.

\section{Sobre la autonomía política y financiera}

La situación en el ámbito autonómico es la misma mutatis mutandis que se acaba de describir en la esfera estatal, con la única diferencia que el equivalente a la soberanía en el Estado es la autonomía política conferida por la Constitución a las comunidades autónomas. En el apartado anterior ya se analizó cómo a medida que se profundiza en la globalización sufren las relaciones de coordinación e inordenación (pérdida de competencias y de potestades para conformar la voluntad estatal), lo que supone, indudablemente, un grave cercenamiento de la autonomía política a medida que se intensifica la globalización. No obstante, no acaba aquí la pérdida de autonomía política, porque ésta integra a la autonomía financiera. No cabe plena autonomía política sin la financiera ${ }^{42}$. Por esta razón, el artículo 156.1 CE confiere a las comunidades autónomas «autonomía financiera para el desarrollo y ejecución de sus competencias con arreglo a los principios de coordinación con la Hacienda estatal y de solidaridad entre todos los españoles».

La autonomía financiera, presupuesto de una plena autonomía política, todavía no ha sido puesta en cuestión por el multilateralismo, pero no está muy lejos en el tiempo. La OMC ya tiene un comité de medidas en materia de Inversiones relacionadas con el comercio, no está tan lejos la liberalización multilateral de los capitales, y los entes territoriales periféricos, como es lógico, no tienen representación directa ante este organismo. La política comercial de los Estados Unidos, desde sus inicios, sanciona en sus Acuerdos de libre comercio la libertad de inversiones, antesala de la libre circulación. Hasta el tipo de Mercado común no había libre circulación de capitales, pero hoy ya hay Acuerdos de libre comercio y Uniones aduaneras que lo prevén ad intra, esto es, entre los Estados miembros. La Unión Europea en su tipo Mercado común la consagró ad intra y cuando inició el camino a la Unidad económica y monetaria supraestatal la sancionó ad extra, esto es, libre circulación de capitales no sólo entre los Estados miembros, sino también abierta al resto del mundo.

${ }^{42}$ La derogada Ley catalana 2/2012 de estabilidad presupuestaria tenía por finalidad, según su artículo 1.2, velar por la autonomía financiera de la Generalidad. Sobre su posible inconstitucionalidad, véase el (un) comentario al Dictamen del Consejo de Estado en GALERA VICTORIA, Adoración, «El legislador autonómico y el principio de estabilidad presupuestaria», Teoría y Realidad Constitucional, n. ${ }^{\circ} 31,2013$, pp. 609 y ss. 


\section{El camino hacia la estabilidad presupuestaria}

La libre circulación de capitales no implica per se una limitación a la autonomía política. La mayor parte de los entes territoriales periféricos no se verán afectados por la libre circulación. No lo serán si mantienen un equilibrio fiscal, entre ingresos y gastos, en el corto, medio y largo plazo; y tampoco si carecen de deuda pública. Ahora bien, pueden ver cercenada su autonomía política si acumulan deuda, hipotecando no sólo el futuro de las nuevas generaciones, sino el margen de discrecionalidad de los futuros representantes de ente regional. La acumulación de deuda pública obliga a realizar emisiones y en un mundo con libre circulación de capitales ésta sólo será cubierta si los fundamentos económicos se consideran ortodoxos, esto es, propios de una política económica liberal en su vertiente de estabilidad financiera ${ }^{43}$. El apartamiento de la ortodoxia económica, con la consecuente reducción de la discrecionalidad política, obligará a pagar más intereses para colocar la deuda, lo que puede llevar en último extremo al default, al hacer inviable el pago de la deuda, de los intereses y de los gastos corrientes. Obviamente, el poder central puede acudir en rescate de la autonomía, siempre que la situación no se haya generalizado al punto de poner en peligro la deuda del propio Estado e, incluso, en estos casos, el poder central puede acudir a su Banco central, que actuaría como prestamista de último recurso; aunque el abuso de esta última situación conduciría a devaluaciones de la propia divisa.

En consecuencia, la libre circulación de capitales ad intra y ad extra obliga a una ortodoxia económica, esto es, a una estabilidad presupuestaria ${ }^{44}$, en su versión más extrema a la regla de oro (golden rule), lo que implica eliminar una parte muy importante del pluralismo político en materia económica, por ejemplo, las políticas keynesianas. Como se ha visto en el párrafo anterior, hay una excepción que consiste en acudir a la función de prestamista de último recurso del Banco central, pero ello conduce antes o después a la devaluación de la divisa, lo que supone un duro castigo a los ciudadanos que se sitúan en posición ahorradora. Lo que explica que existan idearios que se niegan a aceptar esta opción y adoptan posiciones ordoliberales, como

${ }^{43}$ La estabilidad financiera de los entes territoriales periféricos puede lograrse mediante la autocontención, como se indica en el texto, o mediante la imposición por parte del poder central. Sobre esta distinción, específicamente, y sobre la materia tratada en el texto, en general, es imprescindible la consulta a MEDINA GUERRERO, Manuel, «El Estado autonómico en tiempos de disciplina fiscal», Revista Española de Derecho Constitucional, n. ${ }^{\circ} 98,2013$, pp. 112 y 109-147.

${ }^{44}$ En numerosos Estados federales, la ortodoxia económica y la estabilidad presupuestaria se fía a los mercados financieros, véase ANDERSON, George, Fiscal federalism: a comparative introduction, Oxford University Press, 2010, p. 73. También a MEDINA GUERRERO, Manuel, «El Estado autonómico...», ob. cit., p. 130. 
sucede en Alemania, donde hay un cierto consenso al respecto entre los democristianos, los socialdemócratas y los liberales.

Se debe hacer una última consideración, antes de entrar en el mayor embate de la globalización a la autonomía política. La estabilidad presupuestaria puede alcanzarse reduciendo el gasto o elevando los impuestos, como recuerdan algunas posiciones de política económica. Ahora bien, la elevación de impuestos tiene límites evidentes. Una parte importante de las clases medias europeas, concretamente los asalariados, pagan bastante más de la mitad de sus ingresos en tributos y se encuentran, probablemente, en presencia de un sistema fiscal con efectos confiscatorios ${ }^{45}$. Ni siquiera la Unión Europea, y mucho menos los Estados, puede elevar los impuestos a sus multinacionales en gran cuantía por el riesgo de afectarles en su competitividad frente a las radicadas en otros Estados (una decisión del G-20 y su correspondiente implementación sí lo permitiría); y ello por no hablar del posible traslado de la sede fiscal. Se agotan los nichos recaudatorios, resta los impuestos indirectos, que explican la insistencia de la Unión, durante la pasada crisis económica, en que sus Estados miembros recurrieran a aquéllos, especialmente al IVA. Sin animo exhaustivo, hay un tercer elemento relevante que explica por qué la subida de impuestos no siempre es la solución frente al recorte de gastos. La pasada crisis demostró que el enfriamiento de la economía, cuando se produce una crisis tan intensa como la recientemente sufrida, hunde de forma espectacular la recaudación fiscal y que los incrementos en los tipos fiscales, a partir de cierto nivel, no ayudan a mejorar sustancialmente la recaudación, pero sí a enfriar más la economía. Por esta razón hasta los más acérrimos defensores de la estabilidad presupuestaria contemplan como excepción temporal a la misma una crisis económica profunda. Se ha señalado aquí la existencia de ciertos límites a la subida de impuestos a las clases medias y a las empresas, pero la referencia es de carácter general para Europa. En España, la tributación directa a las personas físicas, excepcionados los asalariados, tienen un gran margen todavía, y respecto a las personas jurídicas se estima que también, aunque la certeza en la respuesta requeriría un estudio comparativo tributario específico.

${ }^{45}$ En confrontación con la novedosa, desde una perspectiva de Derecho Constitucional Comparado, prescripción introducida por el artículo 31.1 CE, cuando dispone que «Todos contribuirán al sostenimiento de los gastos públicos [...] mediante un sistema tributario justo [...] que, en ningún caso, tendrá alcance confiscatorio». Nuestro Tribunal Constitucional no se ha pronunciado sobre el límite máximo de progresividad, que no una vez superado adquiere «alcance confiscatorio», pero sí lo ha hecho la sentencia del Tribunal Constitucional alemán de 22 de junio de 1995. Ésta establece que la carga tributaria del sistema fiscal en su conjunto, para no vulnerar el principio de no confiscatoriedad, no debe exceder del cincuenta por ciento de los ingresos del sujeto pasivo. 
Tras estas consideraciones de política económica y tributaria, se enten-

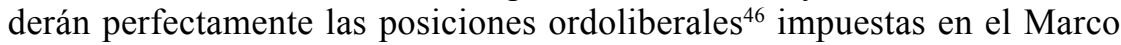
económico de la Unión, que se manifiestan con su máxima intensidad en la política monetaria y en el diseño del Banco Central Europeo ${ }^{47}$. La estabilidad presupuestaria y la prohibición al Banco central de actuar como prestamista de último recurso eran exigencias ordoliberales, emanadas del consenso de la clase política alemana que perseguía una estabilidad de la divisa, imprescindible para su política exportadora, y, en directa relación, un control de la inflación que garantizara la competitividad de la economía europea e impidiera la pérdida de poder adquisitivo de los ahorros de sus ciudadanos.

Con estos presupuestos puede comprenderse que la Unión Europea, cuando inicia el camino de Mercado común a Unidad económica y monetaria supraestatal, impusiera como condición a los Estados para entrar en la moneda única una deuda pública inferior al sesenta por ciento del PIB, una inflación que no difiera en uno y medio por ciento de la de los tres países con menos inflación y un déficit público inferior al tres por ciento. Asimismo, se comprende que la Unión dictara sus primeras directivas y reglamentos destinados a exigir el principio de estabilidad presupuestaria, así como toda la normativa posterior destinada a garantizarla, recurriendo, incluso, a mecanismos coercitivos y sancionadores ${ }^{48}$. También, se entiende la exigencia de

${ }^{46}$ Véase EUCKEN, W., The Foundations of Economics - History and Theory in the Analysis of Economic Reality, Springer, Berlin/New York, 1992; y del mismo autor, «A Policy for Establishing a System of Free Enterprise» en WÜNSCHE, H. F. (Ed.), Standard Texts on the Social Market Economy: Two Centuries of Discussion, Fischer, Stuttgart, 1982, pp. 115-131. Véase GORDILLO PÉREZ, Luis Ignacio, y CANEDO ARRILLAGA, José Ramón, «La Constitución económica de la Unión Europea. Bases de un modelo en constante evolución», Cuadernos de Derecho Transnacional, Vol. 5, n. ${ }^{\circ}$, 2013, pp. 163-183, que cita los anteriores trabajos.

47 CLOSA MONTERO, Carlos J., «Los cambios institucionales en la gobernanza macroeconómica y fiscal de la UE: hacia una mutación constitucional europea», Revista de Estudios Políticos, n. ${ }^{\circ}$ 165, 2014, pp. 70-71, resalta como la gobernanza macroeconómica y fiscal de la UE se inspira en la doctrina del ordoliberalismo alemán que tiene un amplio consenso entre la clase política (CDU-CSU, SPD y FDP) y los economistas. MENÉNDEZ MENÉNDEZ, Agustín, «Integración económica e integración política», $o b$. cit., p. 142, señala: «La fuerte (aunque selectiva) impronta de la tradición constitucional ordoliberal alemana sobre la configuración de la Eurozona se refleja de forma especialmente intensa en la definición de los objetivos de la política monetaria».

${ }^{48}$ El Tratado intergubernamental de Estabilidad, Coordinación y Gobernanza de la Unión Europea y los Reglamentos núms. 1466/1997 y 1467/1997, modificados por el 1175/2011 y 1177/2011, respectivamente, así como la Directiva 2011/85/UE. Lo que se complementa con los Reglamento núms. 1173/2011, 1174/2011y 1176/2011, conjunto de medidas, los citados reglamentos y la directiva, que se conocen como el Six pack. 
introducir clausulas constitucionales de estabilidad presupuestaria ${ }^{49}$, así como la regla de oro, golden rule, aunque ésta resulta de muy difícil encaje en un Estado que se proclama social ${ }^{50}$.

El cumplimiento del principio de estabilidad presupuestaria es exigido por la Unión a sus Estados miembros, únicos responsables ante ella, por lo que éstos se ven obligados a crear mecanismos para obligar a sus entes territoriales periféricos a que se ajusten a la citada estabilidad, ante el riesgo de que un déficit excesivo de éstos conduzca a todo el Estado a una posición de incumplimiento. En este marco se sitúa la Ley Orgánica 2/2012, de 27 de abril, de Estabilidad presupuestaria y Sostenibilidad Financiera ${ }^{51}$, representativa del mayor embate de la globalización a la autonomía política de las comunidades autónomas.

\section{La Ley Orgánica 2/2012, de 27 de abril de Estabilidad presupuestaria y Sostenibilidad financiera}

\subsection{Principios y afección a la autonomía financiera y política}

La Ley Orgánica 2/2012, tras el preámbulo, determina el objeto y su ámbito de aplicación subjetiva. A continuación, con buena técnica constitucionalista (es un ordenamiento eminentemente principialista ${ }^{52}$ ), sanciona siete principios: estabilidad presupuestaria, sostenibilidad financiera, plurianualidad, transparencia, eficiencia en la asignación y utilización de los recursos públicos, responsabilidad, y lealtad institucional. Se estima que los tres principios nucleares de la ley son la estabilidad presupuestaria, la sostenibilidad financiera y el principio de responsabilidad; este último implica que el Estado no asume ni responde de los compromisos financieros asumidos por las comunidades autónomas, esto es, que no se compromete a acudir en su rescate. El principio de transparencia y el de plurianualidad de los presupuestos son instrumentales de los nucleares y facilitan su consecución. El de

${ }^{49}$ Véase GARCÍA ROCA, Javier y MARTÍNEZ LAGO, Miguel Ángel, Estabilidad presupuestaria y consagración del freno constitucional al endeudamiento, Civitas, Madrid, 2013.

${ }_{50}$ Más sentido hubiera tenido la Golden rule en un Estado liberal; Buchanan luchó para realizar una reforma constitucional en los Estados Unidos que introdujera la regla, aunque por escaso margen no lo consiguió.

${ }_{51}$ Que es una consecuencia directa de la reforma del artículo 135.1 y 2 de la CE. Sobre esta Ley Orgánica véase ARIAS ABELLÁN, María Dolores, «Estabilidad presupuestaria y deuda pública: su aplicación a las comunidades autónomas», en Revista d'Estudies Autonomic i Federals, n. ${ }^{\circ}$ 18, 2013, pp. 126 y ss.

52 ARAGÓN REYES, Manuel, Constitución y Democracia, Tecnos, Madrid, 1989, p. 75 . 
eficiencia en la asignación y utilización de los recursos públicos toma como parámetro principal de cumplimiento los tres nucleares; y en la misma línea se mueve el de lealtad institucional, clave en todo Estado compuesto, que encuentra aquí un reconocimiento normativo expreso, tras su deducción implícita de la Constitución por la jurisprudencia ${ }^{53}$.

La cuestión a dilucidar es si el gobierno del poder central vela por el cumplimiento de estos principios, que traen su origen de la integración económica europea y de la globalización y su libre circulación de capitales, respetando el principio de autonomía financiera ${ }^{54}$ y qué supuestos de la ley pueden afectarla ${ }^{55}$.

Los supuestos que afectan a la autonomía financiera de las comunidades son las disposiciones que pretenden garantizar la estabilidad presupuestaria, la sostenibilidad financiera y la fijación del período necesario para no incurrir en morosidad en el pago a proveedores ${ }^{56}$.

La estabilidad financiera afecta a la autonomía financiera de una comunidad porque ésta no puede incurrir en déficit estructural ajustado a un ciclo económico, salvo medidas excepcionales y temporales. Se admite un déficit máximo estructural del cero coma cuatro por ciento del PIB cuando se afronten reformas estructurales destinadas a mejorar el crecimiento económico. Se consideran medidas excepcionales que permiten incurrir en déficit estructural las catástrofes naturales, la recesión económica grave o situaciones de emergencia extraordinaria no previsibles por las administraciones públicas que perjudiquen sustancialmente la situación y sostenibilidad financiera, así como la social. Es importante destacar que la garantía de la estabilidad presupuestaria no opera expresamente sobre los ingresos (impuestos), sino sobre los gastos, cuyo incremento viene determinado por el crecimiento del PIB siempre que no haya desequilibrio estructural en las cuentas públicas o deuda

53 STC 247/2007, FJ 23.

${ }^{54}$ El artículo 10.2 establece de forma reveladora: «Corresponde al Gobierno, sin perjuicio de las competencias del Consejo de Política Fiscal y Financiera de las Comunidades Autónomas y de la Comisión Nacional de Administración Local, y respetando en todo caso el principio de autonomía financiera [...] velar por el cumplimiento de dichos principios $[\ldots] \gg$.

55 Véase DE LA QUADRA-SALCEDO JANINI, Tomás, «¿Se ha transformado la autonomía política y financiera de las Comunidades Autónomas tras la reforma constitucional del artículo 135 y la adopción de la Ley Orgánica 2/2012, de 27 de abril, de Estabilidad Presupuestaria y Sostenibilidad Financiera?», Cuadernos Manuel Jiménez Abad, n. ${ }^{\circ} 6,2013$.

${ }^{56}$ Un amplio estudio sobre el «cerco» que la LO 2/2012 establece sobre el principio de autonomía financiera en CARRASCO DURÁN, Manuel, Estabilidad presupuestaria y comunidades autónomas», en Revista d'Estudies Autonomic i Federals, n. ${ }^{\circ}$ 18, 2013, pp. 169 y ss. 
pública superior a lo determinado. A estos efectos el gobierno central calcula el crecimiento previsto del PIB y el consecuente límite de gasto. La determinación de todos estos parámetros se realiza conforme a la metodología utilizada por la Comisión Europea en aplicación de su normativa.

También afecta a la autonomía financiera la instrumentalización que se realiza de la sostenibilidad financiera que se remite a una deuda pública máxima del sesenta por ciento, respecto al PIB, modificable sólo mediante cambio de la normativa europea. Así como su distribución, un cuarenta y cuatro por ciento para la administración central, un trece para la autonómica, que además se refiere específicamente para cada comunidad, y un tres para la local. Otro tanto sucede cuando las autonomías vulneren el plazo de pago fijado a proveedores, lo que implica una reducción del gasto público que permita restablecer el cumplimiento. Aunque aquí sí se prevé expresamente la subsanación del incumplimiento mediante el incremento de ingresos.

\subsection{Medidas preventivas, correctivas y coercitivas}

El cumplimiento de las exigencias normativas, que persiguen la estabilidad presupuestaria, la sostenibilidad financiera y el cumplimiento del plazo del pago a proveedores, se garantiza a través de medidas preventivas, correctivas y coercitivas.

Las medidas preventivas también son tres. En primer lugar, cuando una comunidad supere el noventa y cinco por ciento en relación al trece por ciento de su PIB regional sólo se le permitirá operaciones de endeudamiento de tesorería. En segundo lugar, si en el seguimiento sobre los periodos medios de pago a proveedores se observa un retraso de más de treinta días, durante dos meses consecutivos, se formula una comunicación de alerta por el Ministerio de Hacienda; ésta indicará el importe que debe dedicar la comunidad autónoma mensualmente al pago a proveedores y las medidas de reducción de gastos o incrementos de ingresos para garantizar que la tesorería pueda cumplir con el objetivo. La medida se mantiene hasta ese momento. En tercer lugar, cuando se apreciare riesgo de incumplimiento del objetivo de estabilidad presupuestaria, de deuda pública o de la regla de gasto, el Gobierno, a propuesta del Ministro de Hacienda, formulará una advertencia motivada. El ente regional tiene un mes para adoptar las medidas necesarias; si no las adopta o son consideradas insuficientes por el Ministerio entran en juego las medidas correctivas.

Las medidas correctivas comienzan porque todas las operaciones de endeudamiento deben ser autorizadas por el poder central. Esta cautela era innecesaria en la pasada crisis económica porque la deuda autonómica de la mayor parte de las comunidades no era cubierta, ya que, como se explicó anteriormente, una de las consecuencias de la libre circulación de capitales es 
que éstos no acuden a cubrir la deuda de aquellos sujetos que han vulnerado la ortodoxia de la política económica liberal, o lo hacen a tipos de interés inasumibles para las autonomías. Ello obligó a crear el Fondo de Liquidez Autonómica por el que el poder central prestaba dinero a las comunidades autónomas. La segunda medida correctiva es la obligación de elaborar un plan económico-financiero, que permita subsanar el incumplimiento en el año en curso y en el siguiente. Si el Consejo de Política Fiscal y Financiera lo estima idóneo, se levanta la obligación de autorización por el poder central de las operaciones de endeudamiento. La última medida correctiva consiste en la elaboración de un plan de reequilibrio cuando una comunidad autónoma haya incurrido en déficit estructural o superación de la deuda pública a consecuencia de una catástrofe natural, recensión económica grave o situación de emergencia extraordinaria. El plan de reequilibrio recogerá detalladamente la senda prevista para restablecer la estabilidad presupuestaria y/o el objetivo de deuda pública fijado.

Los planes económico-financieros y los planes de reequilibrio se encuentran bajo el control del Consejo de Política Fiscal y Financiera, en cuanto a su idoneidad y adecuación, que puede reclamar la elaboración de un nuevo plan que cumpla los objetivos. Si no se presentase o no cumpliese, operan las medidas coercitivas. El Ministerio de Hacienda elabora informes trimestrales de seguimiento del cumplimiento de las medidas contenidas en los planes. Si se verifica una desviación, requerirá a la comunidad autónoma para que la justifique, aplique medidas o implemente otras nuevas que garanticen el cumplimiento del objetivo. Si en el informe del trimestre persiste el incumplimiento, se aplicarán las medidas coercitivas.

Las medidas coercitivas operan cuando falta la presentación o la aprobación o se incumple el plan económico-financiero o el plan de reequilibrio o si se incumple el plazo de pago a proveedores en los términos analizados. La primera medida consiste en la no disponibilidad de créditos; el acuerdo detallará la medida de reducción del gasto e identificará el crédito presupuestario afectado. La segunda medida es un depósito del cero coma dos por ciento del PIB regional en el Banco de España; si a los tres meses no se hubiera presentado o aprobado el plan o no se hubiera aplicado las medidas, el depósito no devenga intereses; si transcurre un nuevo plazo de tres meses y persiste el incumplimiento, el depósito puede convertirse en multa coercitiva. Si resultan insuficientes las anteriores, como tercera medida, el Gobierno podrá enviar, bajo la supervisión del Ministerio de Hacienda, una comisión de expertos para evaluar la situación económico-presupuestaria de la comunidad; aquélla opera al modo de la Troika comunitaria europea, recabando información que les permita presentar una propuesta de medidas que serán de obligado cumplimiento para el ente regional. Finalmente, el incumplimiento de las medidas 
coercitivas anteriores lleva a la puesta en marcha del mecanismo de ejecución autonómica (federal) del artículo $155 \mathrm{CE}^{57}$.

Si se recapitula el contenido de este apartado, se puede concluir que en el momento en que se incurre en un exceso de deuda pública, en desequilibrio presupuestario o en demora en el pago a proveedores se comienza a perder autonomía financiera. Ésta se ve más restringida cuando la comunidad autónoma incurre en la obligación de elaborar un plan económico-financiero o un plan de reequilibrio o ambos. Si se persiste en los incumplimientos y el gobierno central envía a la comisión de expertos, su propuesta de medidas a adoptar, que se recuerda que es vinculante, no afecta a la autonomía financiera de la comunidad e indirectamente a la autonomía política, sino directamente a ésta ${ }^{58}$. La aplicación del artículo 155, dependiendo del alcance concreto de las medidas que se prevean, supone un intervención o suspensión de la autonomía en los ámbitos materiales afectados ${ }^{59}$.

La forma que tiene el poder central de corregir los desequilibrios presupuestarios y los excesos en la deuda pública en la LO 2/2012 se puede considerar que tiene un sesgo que puede agravar la pérdida de autonomía política de las comunidades autónomas. No cabe decir lo mismo en el incumplimiento del plazo en el pago a proveedores; en este caso, el gobierno permite superar la falta de tesorería recortando gastos o incrementando los ingresos, lo que puede hacerse aumentando los impuestos. En cambio, en la exigencia de estabilidad presupuestaria y en el exceso de deuda hay un sesgo tendente a que la comunidad pierda autonomía. Éste consiste en que se pide expresamente recortar el gasto. Se estima que es un sesgo y que no hay agravamiento de la pérdida de autonomía, en principio, porque nada impide que la autonomía suba impuestos, si hay margen, tal y como se indica supra, y logre reducir el porcentaje de deuda fijada o restablezca la estabilidad presupuestaria.

No obstante, a lo reseñado en el párrafo anterior habría que realizar tres consideraciones. El Estado fija un porcentaje en la distribución de la deuda pública de todo el Estado: trece por ciento las comunidades Autónomas, cuarenta y cuatro el poder central y tres por ciento las corporaciones locales. La fijación de estos porcentajes tiene unos amplios márgenes de discrecionalidad y podría ser

57 Véase GARCÍA TORRES, Jesús, «Las medidas necesarias», en el libro La Constitución de los españoles. Estudios en Homenaje a Juan José Solozabal Echavarria, capítulo XXVIII, Centro de Estudios Políticos y Constitucionales, Madrid, 2019, y la bibliografía por él citada.

58 Se coincide con MEDINA GUERRERO, Manuel, «El Estado autonómico...», ob. cit., pp. 142-143, sobre la novedad de la medida en el Derecho constitucional comparado y en su más que probable inconstitucionalidad.

${ }_{59} \mathrm{La}$ LO 2/2012 reduce la discrecionalidad que la Constitución otorga al Gobierno para poner en marcha esta coerción autonómica, lo que no deja de ser cuestionable como señala MEDINA GUERRERO, Manuel, «El Estado autonómico...», ob. cit., p. 144. 
objeto de debate ${ }^{60}$. Por lo que resulta obvio que, si en lugar de fijar un trece para las autonomías se estableciera un quince por ciento, habría más margen y autonomía política y si, por el contrario, se determinara un once, habría menos margen. La segunda consideración hace referencia al mayor margen de maniobra que tiene el poder central de corregir sus desequilibrios incrementando tributos respecto a las comunidades autónomas, lo que se agrava cuando el poder central ha impedido a éstas crear nuevos impuestos como sucedió con los que pretendían gravar las transacciones financieras. Aunque hay que reconocer, también, que la mayor parte de las autonomías tienen, todavía, un amplio margen. Así lo prueba la supresión en algunas del Impuesto sobre Sucesiones y Donaciones. También el poco uso que se ha realizado de recargos sobre impuestos estatales, tras la dura experiencia (coste electoral) de la Comunidad de Madrid en el recargo del IRPF, pocas autonomías se han atrevido a aplicar estas medidas. La tercera y última consideración versa igualmente sobre el mayor margen que posee el Estado central para recortar gastos en el corto plazo frente a las autonomías. El análisis del presupuesto de éstas muestra que prácticamente el setenta por ciento de su gasto está relacionado con el Estado social, en su mayor parte dedicado a sanidad y educación. El poder central puede recortar a corto plazo en inversiones y cumplir el objetivo, cualquier recorte autonómico sustancial, por la configuración de su presupuesto, afecta a la educación y sanidad y tiene un coste electoral mucho más acusado.

\section{AL ESTADO SOCIAL (SANIDAD Y EDUCACIÓN)}

Como se ha venido señalando en el análisis efectuado hasta el momento de la Ley Orgánica de Estabilidad Presupuestaria y Sostenibilidad Financiera, el recorte de gastos ocupa un lugar estelar en la misma. Si se atiende a los presupuestos generales del Estado se observa que hay una partida inamovible, el pago del principal de la deuda pública y sus intereses, lo que ha quedado sancionado tras la reforma constitucional del artículo $135 \mathrm{CE}^{61}$. El presupuesto de la Seguridad Social es una partida prácticamente inamovible, con tendencia al incremento en el gasto de su principal partida, las pensiones, por la composición demográfica actual. En consecuencia, ambas deben ser eliminadas a la hora de analizar la distribución del gasto, susceptible de recorte. Si se atiende a los presupuestos generales del Estado, excluyendo

${ }^{60}$ El preámbulo de la Ley catalana 1/2014 de presupuestos de la Generalidad de Cataluña discrepa con esta distribución y anuncia un requerimiento previo al recurso contencioso-administrativo.

${ }^{61}$ Véase por todos, LÓPEZ GARRIDO, Diego (dir.) y MARTÍNEZ ALARCÓN (coord.), Reforma constitucional y estabilidad presupuestaria. El artículo 135 de la Constitución española, Centro de Estudios Políticos y constitucionales, Madrid, 2013. 
ambas partidas, la distribución del gasto entre las diferentes administraciones es la siguiente: 48 por ciento las comunidades autónomas, 33 el poder central y 19 las corporaciones locales ${ }^{62}$.

El grueso del gasto de ese cuarenta y ocho por ciento, que corresponde a las comunidades autónomas, es destinado a educación y sanidad, concretamente casi un setenta, como se indicó supra. La consecuencia es evidente. La globalización con su libre circulación de capitales y la opción política asumida por la Unión en su Marco económico, con el consecuente recorte del pluralismo político en este ámbito, suponen un embate considerable al Estado social, especialmente en sus vertientes educativa y sanitaria ${ }^{63}$. Éste se incrementa por otro efecto que deriva de la globalización que obliga a la competencia entre integraciones económicas. La Unión Europea lo ha entendido perfectamente y ha marcado en su normativa como objetivo estratégico primordial incrementar su competitividad. El logro a toda costa de este objetivo puede alcanzarse relativizando o minimizando los valores y principios que presiden el ordenamiento comunitario ${ }^{64}$. Así ha ocurrido en las pensiones (Grecia y Portugal) en los derechos de los trabajadores (salarios y condiciones de trabajo) y puede suceder en el medio ambiente. Incluso, se ha visto supra cómo puede condicionar la estructura fiscal, primando los impuestos indirectos frente a los directos o afectando al propio principio de justicia tributaria $^{65}$. Y en lo que aquí interesa, el Estado del bienestar europeo ${ }^{66}$ puede ser concebido como un coste económico susceptible de reducción para mejorar la competitividad, frente a otras integraciones. Es más, algunas opciones ideológicas pueden estar interesadas en su menoscabo y desaparición, porque es indudable que el Estado del bienestar europeo es en la actualidad un faro cuya estela persiguen en buena parte del resto del mundo.

${ }^{62}$ Véase GARCÍA GUERRERO, José Luis, "Lo Stato autonómico...», ob. cit., p. 326 , dato obtenido en 2008 , que no ha sufrido una modificación sustancial.

${ }^{63}$ La Ley catalana 6/2012, de 17 de mayo, de estabilidad presupuestaria, señala expresamente en su preámbulo su preocupación por garantizar el Estado del Bienestar encomendado en su Estatuto. En la misma línea se manifiesta el preámbulo de la Ley 1/2014, de 27 de enero, de presupuestos de la Generalidad de Cataluña para 2014.

${ }^{64}$ Véase CASAS BAAMONDE, María Emilia, «El gobierno económico de la Unión Europea y el Estado social», en el libro Reforma constitucional y estabilidad presupuestaria..., ob. cit., pp. 235-286.

65 Véase NIETO MONTERO, Juan José, «La configuración constitucional de los tributos ante la globalización», en el libro Constitucionalizando la globalización, ob. cit., vol. II, pp. 1535 y ss.

${ }_{66}$ Véase TAJADURA TEJADA, Javier, «La crisis de los derechos sociales en el contexto de la mundialización», en Nuevas Políticas Públicas. Anuario multidisciplinar para la modernización de las Administraciones Públicas, n. ${ }^{\circ}$ 2, 2006, pp. 120-137. Véase también LÓPEZ GARRIDO, Diego, La Edad de Hielo (Europa y Estados Unidos ante la Gran Crisis: el rescate del Estado de bienestar), RBA, Barcelona, 2014. 


\section{CONCLUSIÓN}

A modo de recapitulación de este artículo puede concluirse que la Constitución de 1978 reconoció el pluralismo político y, consecuentemente, la autonomía política. El juego de estos principios constitucionales ha permitido a España transformarse en uno de los Estados más descentralizados del mundo. Aunque es cierto que la autonomía financiera debió esperar hasta avanzados los años noventa para consolidarse ${ }^{67}$; sin embargo, precisamente en esos años surge con fuerza la globalización; ésta y la integración económica en que se incardina España han generado unas condiciones económicas y tomado unas decisiones: Marco económico ordoliberal, libertad de circulación de capitales ad intra de la Unión Europea y ad extra, competitividad, estabilidad presupuestaria (en su variante extrema de la Golden rule) o sostenibilidad financiera; que suponen un significativo embate a la autonomía financiera y, a su través cuando no directamente, a la autonomía política de los entes territoriales periféricos de los Estados compuestos y, por tanto a las comunidades autónomas. Otro tanto puede decirse del Estado Social. Es obligación del constitucionalista dar cuenta de estos problemas, cuyo conocimiento es el presupuesto previo necesario en la búsqueda de soluciones en la pequeña medida que pueda aportar nuestra Ciencia.

\section{BIBLIOGRAFÍA}

Aguiló Regla, J. «Sobre el constitucionalismo y la resistencia constitucional», DOXA: Cuadernos de Filosofía del Derecho, n. ${ }^{\circ} 26,2003$, pp. 289-317.

Aja Fernández, E. El Estado autonómico: federalismo y hechos diferenciales, Alianza Editorial, Madrid, 1999.

ANDERSON, G. Fiscal federalism: a comparative introduction, Oxford University Press, 2010.

Aragón ReYes, M. Constitución y Democracia, Tecnos, Madrid, 1989.

ARIAS ABELLÁN, M. D. «Estabilidad presupuestaria y deuda pública: su aplicación a las comunidades Autónomas», en Revista d'Estudies Autonomic i Federals, n. ${ }^{\circ} 18,2013$, pp. 126-168.

AsenJo, Ó. de J. La Constitución económica española, Centro de Estudios Constitucionales, Madrid, 1984.

BALASSA, B. Teoría de la integración económica, Unión tipográfica editorial hispano-americana, México, 1964.

${ }^{67}$ A pesar del tiempo transcurrido, sigue siendo de gran utilidad en la materia el trabajo de MEDINA GUERRERO, Manuel, La incidencia del sistema de financiación en el ejercicio de las competencias de las comunidades autónomas, Centro de Estudios Constitucionales, Madrid, 1992. 
BÖCKENFÖRDE, E.W. «Los métodos de interpretación constitucional. Inventario y crítica», en el libro Escritos sobres Derechos fundamentales, Nomos Verlagsgesellschaft, Baden-Baden, 1993.

CARrasco DurÁn, M. «Estabilidad presupuestaria y comunidades autónomas», en Revista d'Estudies Autonomic i Federals, n. ${ }^{\circ}$ 18, 2013, pp. 269-206.

Casas BaAmonde, M. E. «El gobierno económico de la Unión Europea y el Estado social», en LóPEz GARRIDO, D. (dir.) y MARTínEZ AlARCón (coord.), Reforma constitucional y estabilidad presupuestaria. El artículo 135 de la Constitución española, Centro de Estudios Políticos y constitucionales, Madrid, 2013.

Cidoncha Martín, A. «El Tribunal Constitucional y la Ley de Garantía de la Unidad de Mercado. Comentario a la STC 79/2017, de 22 de junio de 2017», Revista Española de Derecho Constitucional, n. ${ }^{\circ} 114$, pp. 301-336.

Closa Montero, C. J. «Los cambios institucionales en la gobernanza macroeconómica y fiscal de la UE: hacia una mutación constitucional europea», Revista de Estudios Políticos, n. ${ }^{\circ}$ 165, 2014, pp. 65-94.

COMISIÓN EUROPEA. Documento de reflexión sobre el futuro de las finanzas de la UE, 2017.

ContiPelli, E. «Comunidad Andina de Naciones», en el libro de García Guerrero, J. L. y Martínez Alarcón, M. L. Constitucionalizando la Globalización, vol. I, Tirant Lo Blanch, Valencia, 2019, pp. 281-300.

De La QuAdra-SAlCEDo JANINI, T. Unidad económica y descentralización política, Tirant Lo Blanch, Valencia, 2004.

- Mercado nacional único y Constitución, Centro de Estudios constitucionales, 2008.

— « ¿Se ha transformado la autonomía política y financiera de las Comunidades Autónomas tras la reforma constitucional del artículo 135 y la adopción de la Ley Orgánica 2/2012, de 27 de abril, de Estabilidad Presupuestaria y Sostenibilidad Financiera?», Cuadernos Manuel Jiménez Abad, n. ${ }^{\circ}$ 6, 2013, pp. 59-68.

EUCKEN, W. «A Policy for Establishing a System of Free Enterprise» en Wünsche, H. F. (Ed.), Standard Texts on the Social Market Economy: Two Centuries of Discussion, Fischer, Stuttgart, 1982.

The Foundations of Economics - History and Theory in the Analysis of Economic Reality, Springer, Berlin/New York, 1992.

FERnÁndez FArReres, G. La contribución del Tribunal Constitucional al Estado Autonómico, Iustel, 2005.

Fondo Monetario InTERnACIONAL. World Economic Outlook: Meeting the Challenges of Globalization in the Advanced Economies, Washington D.C., Mayo, 1997.

Font Galán, J. I. Constitución económica y Derecho de la competencia, Tecnos, Madrid, 1987.

GALERA ViCTORIA, A. «El legislador autonómico y el principio de estabilidad presupuestaria», Teoría y Realidad Constitucional, n. . 31, 2013, pp. 609-624.

GARCÍA ECHEVARríA, S. El orden económico en la Constitución, Asociación de Estudios Empresariales, 1978.

GARCÍA GuERRERO, J. L. «Integración económica y reforma constitucional», en el libro colectivo: Visión y análisis comparativo de reformas constitucionales en Iberoamérica, ONU, PUND, Santo Domingo, 2005. 
— «Lo Stato autonómico, evoluzione e e qualche conclusione dopo la prima reforma integrale si alcuni statuti», en el libro Regionalismi e Statuti (Le riforme in Spagna e in Italia), dirigido por GAMBINO, S., Giuffrè, Milano, 2008.

— La publicidad. Fundamentos y límites constitucionales, Tirant Lo Blanch, Valencia, 2014.

— «Las integraciones económicas supraestatales y los acuerdos entre bloques económicos, en definitiva, la globalización como último embate al concepto racional normativo de Constitución», en el libro Constitución, Justicia constitucional y Derecho procesal constitucional (Liber Amicorum en Homenaje al profesor Dr. Juan Manuel Pellerano Gómez), coordinado por JoRge Prats, E. y VALERIO JiMENIÁN, M., Instituto Dominicano de Derecho Constitucional y Librería Jurídica Internacional, Santo Domingo, República Dominicana, 2014.

García Guerrero, J. L., y Martínez Alarcón, M. L., Constitucionalizando la globalización, capítulo I, y en general vol. I y vol. II, Tirant Lo Blanch, Valencia, 2019.

García Pelayo, M., Derecho Constitucional Comparado, Alianza Editorial, Madrid, 1984.

García RocA, J. y MARtínez LAGo, M. Á. Estabilidad presupuestaria y consagración del freno constitucional al endeudamiento, Civitas, Madrid, 2013.

GARCÍA TORRES, J. «Las medidas necesarias», en el libro La Constitución de los españoles. Estudios en Homenaje a Juan José Solozabal Echavarria, capítulo XXVIII, Centro de Estudios Políticos y Constitucionales, Madrid, 2019.

García Victoria, I. «Unidad Económica supraestatal», en el libro de García GueRrero, J. L., y Martínez Alarcón, M. L. Constitucionalizando la Globalización, vol. I, Tirant Lo Blanch, Valencia, 2019, pp. 225-250.

GLitz, F. E. Z., «Los 25 años del MERCOSUR y las perspectivas jurídicas del proceso de integración sudamericana», en el libro de GARCía Guerrero, J. L. y Martínez Alarcón, M. L., Constitucionalizando la Globalización, vol. I, Tirant Lo Blanch, Valencia, 2019, pp. 369-392.

GonzÁlez JimÉnEZ, M. «Esbozo de una teoría general del Mercado común como modalidad de integración económica», en el libro de GARCía GUERRERO, J. L., y Martínez Alarcón, M. L., Constitucionalizando la Globalización, vol. I, Tirant Lo Blanch, Valencia, 2019, pp. 187-224.

Gordillo Pérez, L. I., y Canedo Arrillaga, J. R. «La Constitución económica de la Unión Europea. Bases de un modelo en constante evolución», Cuadernos de Derecho Transnacional, Vol. 5, n. ${ }^{\circ}$ 1, 2013, pp. 163-183.

Heller. La soberanía, Universidad Nacional Autónoma de México, México DF, 1965.

Hesse, K. Escritos de Derecho Constitucional, Centro de Estudios Constitucionales, Madrid, 1992.

Krasner, S. D. Soberanía: Hipocresía organizada, Paidós, 2001.

Krugman, P. y De La Dehesa, G. Economic and Monetary Unions and the Regions, Group of Thirty, 1995.

López Castillo, A.; Sainz Arnaiz, A. y Ferreres Comella, V. Constitución española y Constitución europea: Análisis de la Declaración del Tribunal Constitu- 
cional (DTC-1/2004, de 13 de diciembre), Centro de Estudios Políticos y Constitucionales, Madrid, 2005.

López Garrido, D. La Edad de Hielo (Europa y Estados Unidos ante la Gran Crisis: el rescate del Estado de bienestar), RBA, Barcelona, 2014.

LÓPEZ GARRIDO, D. (dir.) y MARTÍNEZ AlARCón (coord.), Reforma constitucional y estabilidad presupuestaria. El artículo 135 de la Constitución española, Centro de Estudios Políticos y constitucionales, Madrid, 2013.

Medina Guerrero, M. La incidencia del sistema de financiación en el ejercicio de las competencias de las comunidades autónomas, Centro de Estudios Constitucionales, Madrid, 1992.

— «El Estado autonómico en tiempos de disciplina fiscal», Revista Española de Derecho Constitucional, n. ${ }^{\circ}$ 98, 2013, pp. 109-147.

Meix Cereceda, P. «La Unidad Económica y Monetaria supraestatal», en el libro de García Guerrero, J. L., y Martínez Alarcón, M. L., Constitucionalizando la Globalización, vol. I, Tirant Lo Blanch, Valencia, 2019, pp. 251-280.

MENÉNDEZ MENÉNDEZ, A. «Integración económica e integración política», en el libro dirigido por LóPez CAstillo, A. Instituciones y Derecho de la Unión Europea, vol. I, Tirant Lo Blanch, Valencia, 2015.

Nieto Montero, J. J. «La configuración constitucional de los tributos ante la globalización», en el libro de García Guerrero, J. L. y Martínez Alarcón, M. L., Constitucionalizando la Globalización, vol. II, Tirant Lo Blanch, Valencia, 2019, pp. 1535-1574.

RODRIK, D. La paradoja de la globalización (Democracia y el futuro de la economía mundial), Antoni Bosch, Barcelona, 2011.

RUBio Llorente, F. «Globalización económica y reforma constitucional», Revista de Occidente, n. ${ }^{\circ}$ 388, 2013, pp. 5-20.

SASSEn, S. ¿Perdiendo el control? La soberanía en la era de la globalización, Barcelona, Bellaterra, 2001.

SCHNEIDER, J.-P., «Continencia judicial y estructura normativa abierta del Derecho Constitucional», en el libro dirigido por LóPEZ PINA, A. División de poderes e interpretación (hacia una teoría de la praxis constitucional, Tecnos, Madrid, 1987.

Solozabal Echavarria, J. J., Bases constitucionales del Estado autonómico, McGraw-Hill, Madrid, 1988.

— Nación y Constitución: soberanía y autonomía en la forma política, Biblioteca Nueva, 2004.

- Tiempo de reformas: el Estado autonómico en cuestión, Biblioteca Nueva, 2006.

Stiglitz, J. E.; Sen, A. y Fitoussi, J.-P., Mismeasuring Our Lives: Why GDP Doesn't Add Up, The New Press, 2010.

TAIBO, C. Para entender el TIPP (Una visión crítica del Acuerdo Transatlántico de comercio e inversiones), Catarata, Madrid, 2016.

TAJAdura TeJadA, J. «La crisis de los derechos sociales en el contexto de la mundialización», en Nuevas Políticas Públicas. Anuario multidisciplinar para la modernización de las Administraciones Públicas, n. ${ }^{\circ}$ 2, 2006, pp. 120-137. 
TORRENT, R. La integración regional ante un nuevo cambio de paradigma: reflexiones desde una perspectiva histórica y comparada, Sieca, 2009.

Viciano PASTOR, R. «Problemas de legitimidad constitucional de las integraciones supranacionales», Cuadernos constitucionales de la Cátedra Fadrique Furiol, n. ${ }^{\circ}$ 67-68, 2009, pp. 91-99.

WYDUCKEL, D., «La soberanía en la historia de la dogmática alemana», Fundamentos. Cuadernos monográficos de Teoría del Estado, Derecho Público e Historia Constitucional, n. ${ }^{\circ}$ 1, monográfico sobre «Soberanía y Constitución», Junta General del Principado de Asturias, 1998, pp. 203-294. 


\title{
GLOBALIZACIÓN, ESTABILIDAD PRESUPUESTARIA Y COMUNIDADES AUTÓNOMAS
}

\author{
Globalization, Budget Stability \\ and Autonomous Communities
}

\author{
José Luis García Guerrero \\ Profesor Titular (ApC) Derecho constitucional \\ Universidad de Castilla - La Mancha
}

http://dx.doi.org/10.18543/ed-67(1)-2019pp223-258

\section{Copyright}

Estudios de Deusto es una revista de acceso abierto, lo que significa que es de libre acceso en su in tegridad. Se permite su lectura, la búsqueda, descarga, distribución y reutilización legal en cualquier tipo de soporte sólo para fines no comerciales, sin la previa autorización del editor o el autor, siempre que la obra original sea debidamente citada y cualquier cambio en el original esté claramente indicado

Estudios de Deusto is an Open Access journal which means that it is free for full access, reading, search, download, distribution, and lawful reuse in any medium only for non-commercial purposes, without prior permission from the Publisher or the author; provided the original work is properly cited and any changes to the original are clearly indicated. 